\title{
Sistem Pemantau Gas di Tempat Pembuangan Sampah Akhir Berbasis Internet of Things
}

\author{
Fathur Zaini Rachman*) \\ Teknik Elektronika, Politeknik Negeri Balikpapan \\ Jl. Soekarno Hatta KM.08, Balikpapan, Indonesia 76127
}

Cara sitasi: F. Z. Rachman, "Sistem Pemantau Gas di Tempat Pembuangan Sampah Akhir Berbasis Internet of Things," Jurnal Teknologi dan Sistem Komputer, vol. 6, no. 3, Jul. 2018. doi: 10.14710/jtsiskom.6.3.2018.100-105, [Online].

\begin{abstract}
This research developed a gas monitoring system in the landfill. The system has implemented the Internet of Things (IoT) using the ESP8266 Wi-Fi module to transmit methane $\left(\mathrm{CH}_{4}\right)$ and carbon dioxide $\left(\mathrm{CO}_{2}\right)$ data concentration, as well as temperature and humidity to the ThingSpeak server. Users can monitor and access these environmental data through social media Twitter and websites from anywhere. The fastest data delivery can be obtained with a time interval of 16 seconds on each data packet sent when there is an Internet connection.
\end{abstract}

Keywords - gas monitoring system; $\mathrm{CH}_{4}$ and $\mathrm{CO}_{2}$ measurements; landfill gas monitoring; environmental IoT

\begin{abstract}
Abstrak - Penelitian ini mengembangkan sistem pemantau gas berbahaya di tempat pembuangan sampah akhir. Sistem ini telah mengimplementasikan Internet of Things (IoT) menggunakan modul Wi-Fi ESP8266 untuk mengirimkan hasil pemantauan konsentrasi gas metana $\left(\mathrm{CH}_{4}\right)$ dan karbon dioksida $\left(\mathrm{CO}_{2}\right)$ serta suhu dan kelembaban ke server ThingSpeak. Pengguna dapat memperoleh dan mengakses data lingkungan ini melalui media sosial Twitter dan situs web dari mana saja. Pengiriman data tercepat diperoleh dengan interval waktu 16 detik untuk setiap pengiriman paket data saat terdapat koneksi Internet.
\end{abstract}

Kata Kunci - sistem pemantau gas; pengukuran $\mathrm{CH}_{4}$ dan $\mathrm{CO}_{2}$; pemantauan pembuangan sampah; IoT untuk lingkungan

\section{Pendahuluan}

Dengan adanya tempat pembuangan sampah akhir (TPA) maka akan diikuti dampak terhadap lingkungan, selain dampak positif dari komponen biofisik, biotis dan sosekbudkesmas [1]. Dampak negatif tersebut adalah dihasilkannya timbulan gas dan lindi yang sangat berpotensi merusak kesehatan masyarakat di lingkungan TPA, baik dari pencemaran air oleh zat padat tersuspensi [2] maupun risiko paparan gas dari TPA

\footnotetext{
*) Penulis korespondensi (Fathur Zaini Rachman)

Email: fathur.zaini@poltekba.ac.id
}

terhadap gangguan pernapasan [3]. Alat yang dapat digunakan untuk mengumpulkan data tingkat konsentrasi gas yang lepas ke atmosfer di TPA perlu dikembangkan.

Gas yang berasal dari TPA di antaranya adalah gas metana $\left(\mathrm{CH}_{4}\right)$. Beragam pengembangan dan metode telah dilakukan untuk merancang instrumen yang dapat mengukur gas tersebut [4]-[7]. Astika dan Zulfahmi [4] menggunakan teknologi sinar inframerah untuk mendeteksi gas metana di tambang batubara bawah tanah. Sensor TGS 2611 digunakan dalam [5], [6] untuk mengukur konsentrasi gas metana di lahan gambut dan TPA, sedangkan Alfanz dkk. [7] mengimplementasikan sensor MQ4 untuk memantau metana dalam produksi biogas, selain kadar oksigen dan karbon dioksida $\left(\mathrm{CO}_{2}\right)$.

Instrumen pemantau dan pendeteksi gas metana tersebut di atas masih dioperasikan secara lokal di tempat pengukuran. Hasil pengukuran ditampilkan dalam LCD seperti dalam [5], [6], di layar komputer seperti dalam [5], [7] atau disimpan dalam media penyimpan portabel SD/MMC seperti dalam [4] untuk diambil dan diolah dengan komputer pada waktu tertentu. Pengukuran langsung di lokasi membutuhkan perilaku khusus dalam mengukur agar tidak membahayakan pengambil data dan tidak bisa dilakukan sepanjang waktu.

Di sisi lain, beragam sistem pemantau lingkungan menggunakan media nirkabel telah dikembangkan untuk mengirimkan data pemantauan ke lokasi berjauhan [8]-[12]. Sistem dalam [8], [9] memantau parameter lingkungan, seperti konsentrasi $\mathrm{CO}, \mathrm{NO} 2$, kepadatan debu, kelembaban dan suhu serta mengirimkan datanya ke server secara nirkabel menggunakan modul nRF24L01. Modul Xbee digunakan dalam [10], [11] untuk mengirimkan data dalam aplikasi rumah cerdas serta memantau dan mengendalikan ruang dari jarak jauh menggunakan protokol ZigBee, sedangkan dalam [12], modul ESP8266 digunakan dalam aplikasi infus pasien untuk mengirimkan data nirkabel dengan Wi-Fi.

Berbeda dengan [4]-[7] yang mengembangkan pemantau TPA secara lokal, penelitian ini mengembangkan sistem pemantau konsentrasi gas metana dan karbon dioksida serta kelembaban dan suhu di TPA secara lokal dan jarak jauh menggunakan media nirkabel. Sistem menggunakan sensor MQ4 untuk 


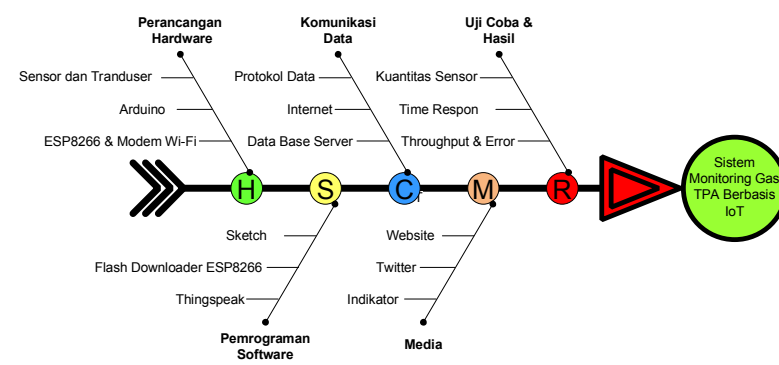

Gambar 1. Konsep pengembangan sistem pemantau gas TPA dengan IoT

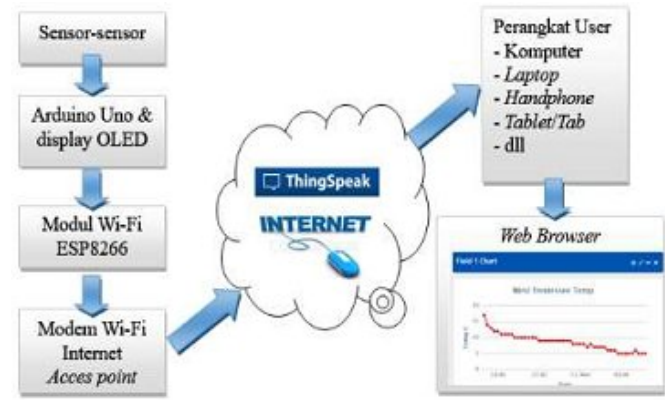

Gambar 2. Diagram kerja sistem pemantauan gas TPA

mengukur konsentrasi gas metana dan MQ135 untuk gas karbon dioksida. Data-data pemantauan di TPA tersebut selain ditampilkan di layar OLED LCD, juga dikirimkan secara nirkabel menggunakan modul Wi-Fi ESP 8266 ke server ThingSpeak, seperti dalam [12]. Sistem ini diintegrasikan dengan Twitter sehingga pengguna dapat mengakses informasi kondisi TPA melalui media sosial dengan cepat. Sistem juga mempunyai indikator lampu dan sirine jika dalam kondisi bahaya sehingga beragam upaya dapat dilakukan untuk pencegahan bahaya gas TPA secara dini.

\section{Metode Penelitian}

Konsep pengembangan sistem pemantau gas di TPA berbasis IoT ditunjukkan dalam Gambar 1. Dalam perancangan hardware dilakukan pengkabelan dan pengaturan tata letak dari semua komponen dan modul. Arduino Uno menjadi pusat pemrosesan informasi dari sensor dan diolah menjadi informasi agar dapat dikirim ke server ThingSpeak sebagai media penyimpan data sensor. Perancangan dan implementasi pemrograman di Arduino menggunakan Sketch dan bahasa C.

Diagram kerja sistem yang menunjukkan komponen dan alur kerjanya dinyatakan dalam Gambar 2. Masukan sistem berasal dari sensor-sensor gas metana, karbon dioksida, suhu dan kelembaban. Sensor gas metana menggunakan MQ4, sedangkan sensor gas karbon dioksida menggunakan MQ135, masing-masing dengan jangkauan 200-10,000 PPM. Sensor kelembaban dan suhu menggunakan DHT 11. Sensor MQ4 dan MQ135 menggunakan antarmuka analog Arduino di A3 dan A5, sedangkan DHT 11 menggunakan antarmuka digital D5 dan menggunakan format data serial.

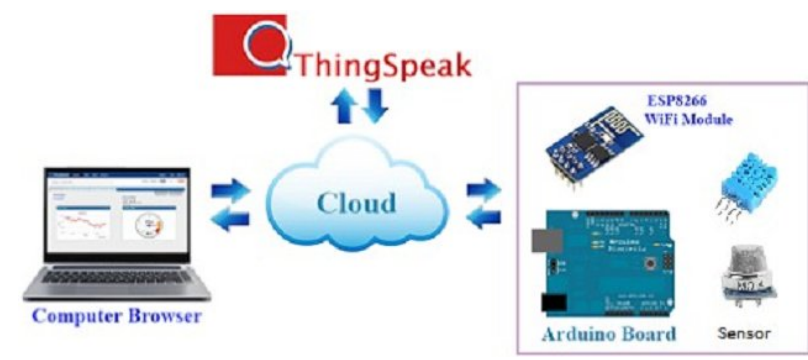

Gambar 3. Proses dan komunikasi antar sistem

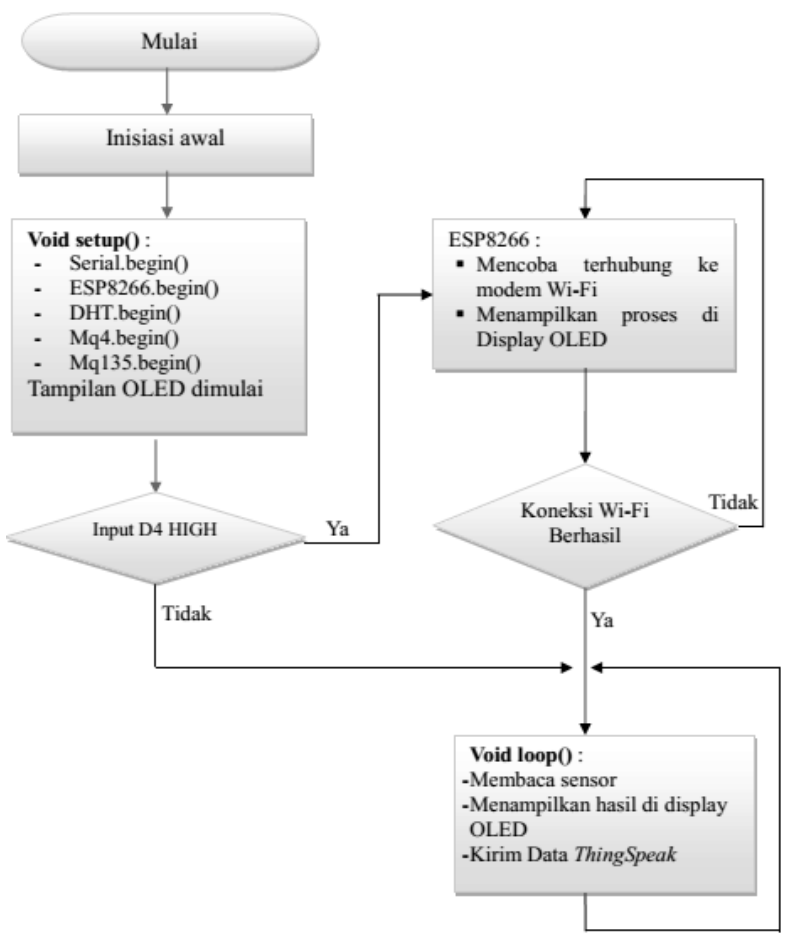

Gambar 4. Diagram alir program Arduino Uno

Antarmuka tampilan ke pengguna menggunakan OLED LCD yang terpasang pada prototipe untuk menampilkan nilai terukur di layar. Dalam prototipe juga terdapat indikator berupa alarm dan lampu tanda bahaya sebagai informasi dini akan gas berbahaya di wilayah TPA. Antarmuka OLED ke Arduino menggunakan serial sinkron I2C.

Modul komunikasi menggunakan ESP8266 sebagai media komunikasi melalui $\mathrm{WiFi}$ pita $2,4 \mathrm{GHz}$ terhadap server ThingSpeak sehingga data dapat tersedia di Internet dan dapat diakses publik, seperti ditunjukkan dalam Gambar 3. ThingSpeak menyediakan aplikasi IoT untuk mengunggah dan mengunduh data menggunakan HTTP. Aplikasi ThingTweet dan React dapat dikombinasikan di ThingSpeak sehingga bisa dipakai memberikan notifikasi peringatan dini jika level konsentrasi gas mencapai angka tertentu. Akses melalui laman server ThingSpeak dilakukan melalui browser web dan notifikasi informasi disampaikan melalui media sosial Twitter.

Diagram alir program Arduino Uno untuk sistem pemantau gas di TPA ditunjukkan dalam Gambar 4. 


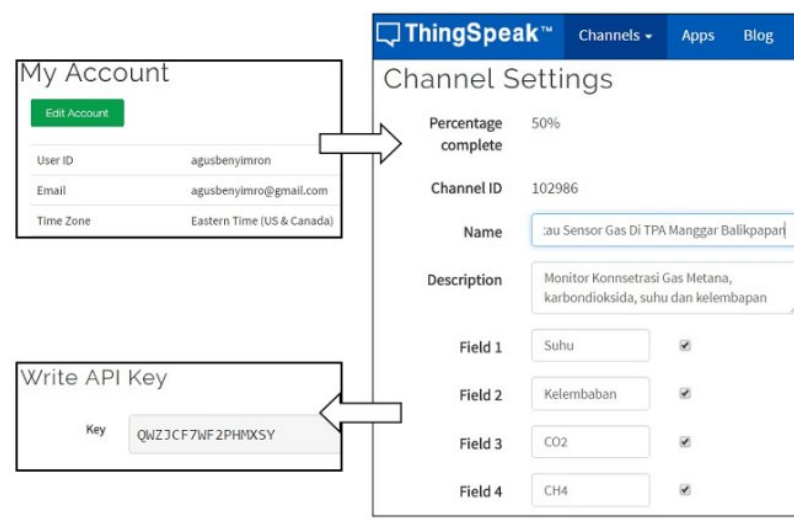

Gambar 5. Akun dan channel baru ThingSpeak untuk aplikasi pemantau gas di TPA

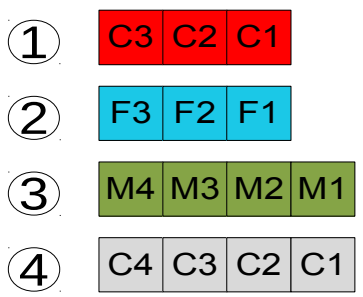

Gambar 6. Format data sensor

Proses inisiasi (setup) di awal program dilakukan dengan memanggil pustaka yang diperlukan untuk sensor, OLED dan modul ESP8266, penentuan kaki pin yang digunakan, konstanta dan isi variabel. Fungsi pengulangan (loop) melakukan pembacaan data-data sensor, konversi data pembacaan sensor menjadi variabel string dan menampilkannya ke LCD OLED, dan mengirimkan data-data tersebut ke ThingSpeak.

Implementasi program di ThingSpeak dilakukan dengan mendaftarkan aplikasi (channel) ke akun pengembang. Dalam penelitian ini, channel baru berisi empat field untuk menyimpan pembacaan suhu, kelembaban, karbon dioksida dan metana (Gambar 5). Channel ID dan kunci API ditanamkan dalam program Arduino. Fasilitas Twitter menggunakan ThingTweet dan React yang diatur dalam ThingSpeak.

Protokol komunikasi data yang digunakan dalam penelitian ini agar data dapat dikirim melalui jaringan Internet dan disimpan dan ditampilkan pada server ThinkSpeak. Format data dari sensor melalui ThinkSpeak ditunjukkan dalam Gambar 6. Data yang dikirim ada 4 data, yaitu data untuk suhu (1), data kelembaban (2), data gas metana (3) dan data karbon dioksida (4).

Pengujian kinerja transmisi data yang dilakukan adalah pengukuran packet loss terhadap variasi interval pengiriman. Packet loss ini menunjukkan banyaknya data yang hilang sehingga paket data tidak diterima oleh koordinator dengan banyaknya data yang telah dikirim oleh perangkat pada satu pengukuran. Perhitungan packet loss dinyatakan dalam Persamaan 1. Parameter PLx menyatakan persentasi packet loss, $\mathrm{nRx}$ menyatakan jumlah data diterima dan nTx menyatakan jumlah data yang dikirim.

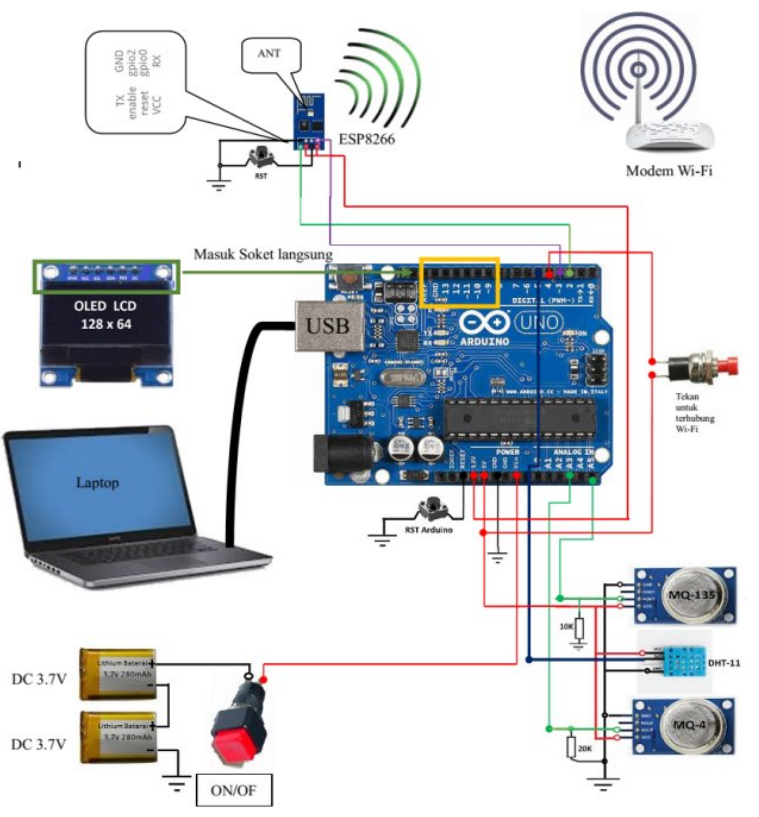

Gambar 7. Diagram susunan modul dalam sistem dan interkoneksinya

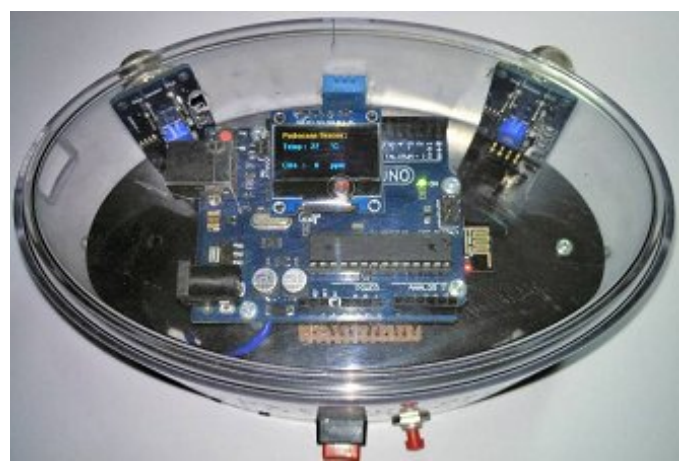

Gambar 8. Prototipe sistem pemantau gas siap diuji di TPA Manggar Balikpapan

$$
P L_{x}=\left(1-\frac{n R x}{n T x}\right) \times 100 \%
$$

\section{Hasil dan Pembahasan}

Hasil pengembangan sistem ditunjukkan dalam diagram pengkabelan (Gambar 7) dan prototipe sistem (Gambar 8). Diagram pemasangan sistem memberikan gambaran utuh dan jelas tentang susunan modul, interkoneksi dan fungsinya. Prototipe sistem telah siap untuk diuji coba langsung di TPA Manggar Balikpapan untuk pemantauan konsentrasi gas metana dan karbon dioksida serta kelembaban dan suhu di lingkungan tersebut secara nirkabel.

Pengujian sistem di TPA Manggar dilakukan dengan perantara selang agar hasil yang diperoleh maksimal seperti ditunjukkan dalam Gambar 9. Dalam pengujian, data pemantauan lengkap dapat diamati dari pembacaan di serial monitor Arduino (Gambar 10). Penggunaan serial monitor ini adalah hanya dalam pengujian saja, sedangkan dalam operasi sistem, data pemantauan 


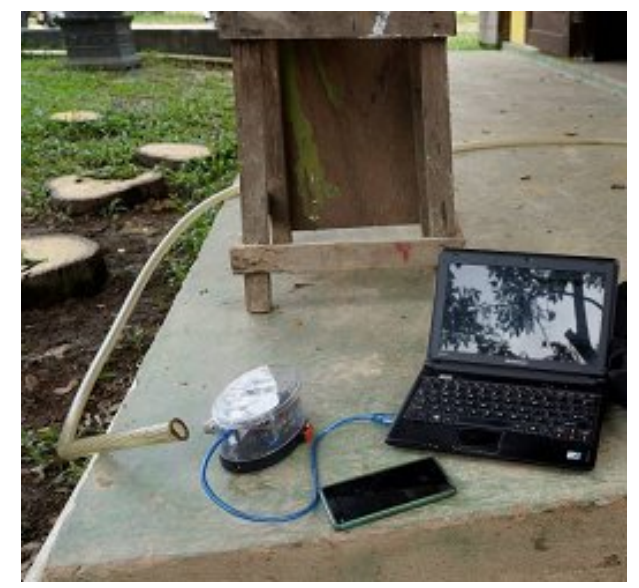

Gambar 9. Pengujian sistem di TPA Manggar

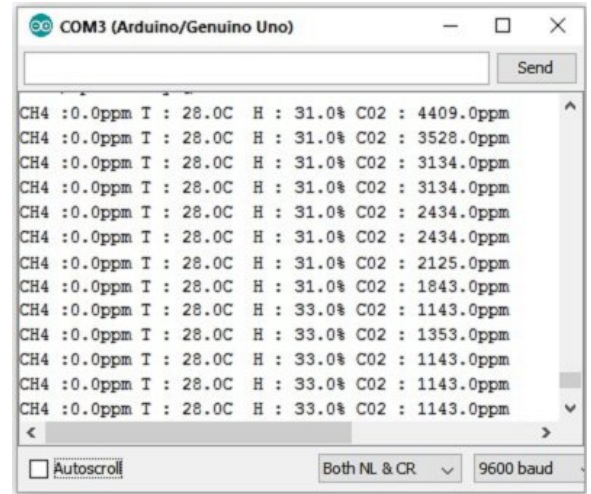

Gambar 10. Hasil pengujian sensor di serial monitor

ditampilkan di layar LCD OLED dan dikirimkan ke server ThinkSpeak melalui antarmuka ESP8266.

Pengujian sensor dilakukan untuk menguji fungsionalitas pembacaan sensor MQ4, MQ135 dan DHT11. Dalam operasinya, pembacaan sensor MQ ditunda sekitar 3 menit untuk memanaskan filamennya. Hasil pembacaan konsentrasi gas, kelembaban dan suhu ditampilkan di layar LCD OLED (Gambar 11) dan jendela aplikasi ThinkSpeak (Gambar 12).

Perubahan pada data sensor dapat dipantau secara real-time, baik di lokasi seperti dalam [4]-[7] maupun dari jarak jauh menggunakan browser web seperti dalam [8]-[12]. Sistem ini telah dapat mengirimkan notifikasi bahaya saat konsentrasi gas metana melebihi 5000 ppm melalui media sosial Twitter (Gambar 13). Informasi ini dapat didapatkan oleh pengguna yang mengikuti (follow) akun Twitter TPA Manggar.

Sistem telah dapat melakukan pengukuran konsentrasi gas metana, karbon dioksida, suhu dan kelembaban dengan baik. Penelitian ini menggunakan pustaka Arduino standar untuk konversi nilai pembacaan sensor ke parameter lingkungan, seperti halnya yang dilakukan dalam [5]-[7], sehingga akurasi pembacaan sensor belum teruji. Pengujian akurasi sensor gas metana telah dilakukan dalam [4] yang menggunakan sensor inframerah dan pembanding detektor multigas. Kesalahan pembacaan sensor SHT11

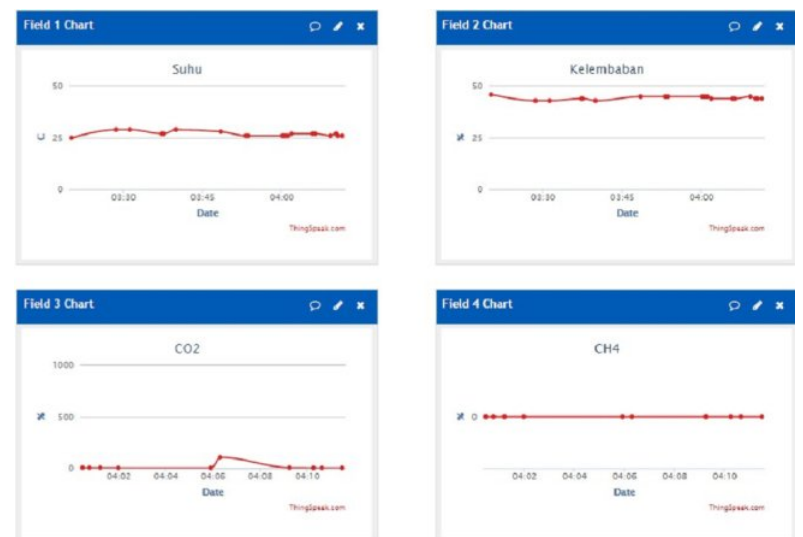

Gambar 11. Tampilan data pemantauan di ThinkSpeak

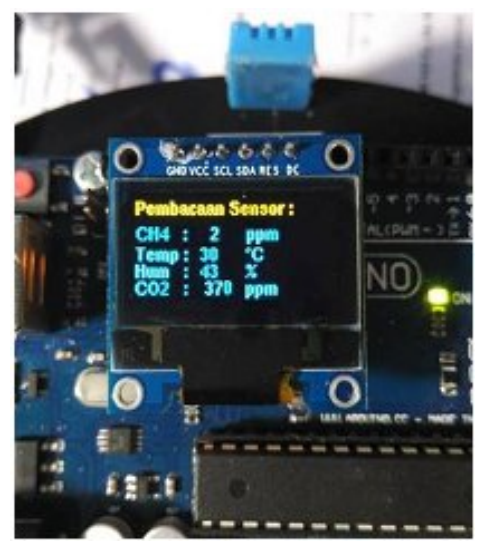

Gambar 12. Tampilan data pembacaan di LCD OLED

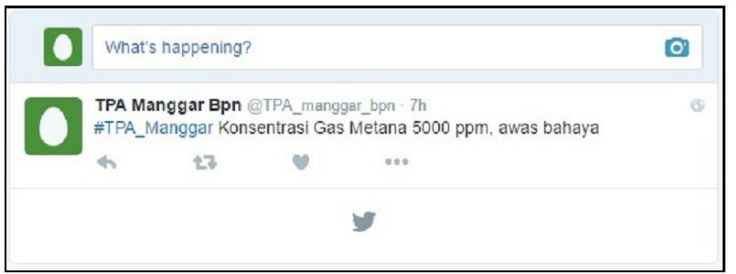

Gambar 13. Notifikasi bahaya gas TPA di Twitter

adalah sebesar $0,22^{\circ} \mathrm{C}$ untuk suhu dan $0.98 \%$ untuk kelembaban [8].

Sistem telah dapat mengirimkan paket data ke server ThingSpeak secara periodik. Paket data dalam setiap pengirimannya adalah sebesar 14 Byte. Pengujian performansi dilakukan dengan variasi interval tiap pengiriman dan dilakukan selama 1 menit. Besar data terkirim oleh alat dan diterima oleh server selama 1 menit diukur untuk menghitung packet loss-nya $\left(\mathrm{PL}_{\mathrm{T}}\right)$ menggunakan Persamaan 1. Hasil pengujian ditunjukkan dalam Tabel 1. Hasil tersebut menunjukkan bahwa terdapat paket yang hilang saat interval antar pengiriman kurang dari 16 detik. Pengiriman terbaik tiap pengiriman terjadi pada interval 16 detik.

Batasan sistem dalam interval pengiriman paket data sebesar 16 detik tersebut menyebabkan pembaruan data di ThingSpeak juga paling cepat 16 detik tiap data. Interval yang kurang dari 16 detik menyebabkan 
Tabel 1. Variasi interval waktu pengiriman terhadap Packet Loss

\begin{tabular}{rccccc} 
No & $\begin{array}{c}\text { Interval } \\
\text { (detik) }\end{array}$ & $\begin{array}{c}\text { Besar paket } \\
\text { (byte) }\end{array}$ & $\begin{array}{c}\text { Tx / menit } \\
\text { (byte) }\end{array}$ & $\begin{array}{c}\boldsymbol{R} \boldsymbol{x} / \text { menit } \\
\text { (byte) }\end{array}$ & $\boldsymbol{P L}_{\boldsymbol{T}}(\mathbf{\%})$ \\
\hline 1 & 2 & 14 & 434 & 56 & 675 \\
2 & 4 & 14 & 224 & 56 & 300 \\
3 & 6 & 14 & 154 & 56 & 175 \\
4 & 8 & 14 & 112 & 56 & 100 \\
5 & 10 & 14 & 98 & 56 & 75 \\
6 & 12 & 14 & 70 & 56 & 25 \\
7 & 14 & 14 & 70 & 56 & 25 \\
8 & 16 & 14 & 56 & 56 & 0 \\
9 & 18 & 14 & 56 & 56 & 0 \\
10 & 20 & 14 & 56 & 56 & 0 \\
11 & 22 & 14 & 42 & 42 & 0 \\
12 & 24 & 14 & 42 & 42 & 0 \\
\hline
\end{tabular}

kesalahan dalam pembacaan ThinkSpeak (status ThingSpeak: Error), sedangkan jika lebih dari 16 detik, pembaruan data berhasil (status Update to ThingSpeak $O K)$. Pembaruan data setiap 16 detik ini sudah cukup memadai dengan perubahan nilai konsentrasi gas metana, karbon dioksida, suhu dan kelembaban yang tidak ekstrem (lambat). Untuk menghemat jumlah data terkirim ke ThingSpeak, interval waktu pengiriman juga bisa diatur sesuai kebutuhan.

Koneksi Internet yang memadai diperlukan agar kerja sistem secara keseluruhan untuk memantau konsentrasi gas metana, gas karbon dioksida, suhu dan kelembaban dapat berjalan dengan baik [12]. Hal ini umumnya menjadi kendala dalam implementasi pemantauan jarak jauh di TPA, termasuk di TPA Manggar. Untuk komunikasi jarak jauh, modul nRF905 dapat digunakan seperti dalam [14] untuk pengiriman data dari node sensor ke koordinator sebelum dikirimkan lewat Internet ke ThingSpeak. Modul ini dapat mengirimkan data sampai jarak 245 meter.

Pemantauan konsentrasi gas di beberapa titik juga dapat dilakukan dengan multinode nirkabel agar sebaran gas metana dapat diukur seperti dalam [6]. Penambahan sensor pengukur parameter lingkungan masih dapat dilakukan, misalnya untuk mengukur komponen geofisika tanah TPA seperti kelembaban dan kegemburan tanah [1] serta untuk mengukur zat padat tersuspensi, $\mathrm{NH}_{3}$ dan $\mathrm{H}_{2} \mathrm{~S}$ yang juga membawa dampak kesehatan menurut [2], [3].

\section{KESIMPULAN}

Sistem pemantauan gas berbasis IoT telah berhasil dikembangkan untuk mengukur konsentrasi gas metana, karbon dioksida, suhu dan kelembaban di TPA. Data pengukuran telah dapat ditampilkan di layar LCD OLED untuk pemantauan lokal dan dikirimkan ke server ThingSpeak untuk pemantauan jarak jauh yang dapat diakses melalui browser web secara real-time setiap 16 detik. Notifikasi bahaya gas telah dapat dikirimkan lewat media sosial Twitter.

\section{UCAPAN TERIMA KASIH}

Penelitian ini dibiayai oleh P3M Politeknik Negeri Balikpapan dan didukung oleh TPA Manggar Balikpapan yang menyediakan tempat dalam uji coba hasil penelitian ini.

\section{Daftar Pustaka}

[1] T. Sukrorini, "Kajian Dampak Timbunan Sampah terhadap Lingkungan di Tempat Pembuangan Akhir (TPA) Putri Cempo Surakarta," Tesis, Universitas Sebelas Maret, Surakarta, 2014.

[2] S. Sabella, "Risiko Gangguan Kesehatan pada Masyarakat di Sekitar Tempat Pembuangan Akhir (TPA) Sampah Tanjungrejo Kabupaten Kudus," Skripsi, Universitas Negeri Semarang, Semarang, Maret 2014.

[3] A. D. Firdaus, "Analisis Resiko Pajanan NH3 dan H2S Terhadap Gangguan Pernapasan pada Penduduk di Sekitar Pembuangan Akhir Sampah Bukit Pinang Samarinda," Jurnal Kesehatan Masyarakat, vol. 2, no. 1, pp. 49-56, 2016

[4] H. Astika and Z. Zulfahmi, "Aplikasi Pendeteksi Gas Metana Menggunakan Teknologi Sinar Infra Merah pada Tambang Batubara Bawah Tanah," Jurnal Teknologi Mineral dan Batubara, vol. 9, no. 1, pp. 1-10, 2013.

[5] I. Sugriwan, A. J. Fuadi, and S. Riadi, "Desain dan Fabrikasi Alat Ukur Kadar Gas Metana (CH4) pada Lahan Gambut Menggunakan Sensor TGS2611 Berbasis ATMega8535," Jurnal Neutrino, vol. 8, no. 1, pp. 11-20, Oktober 2015.

[6] S. I. Masruroh, "Deteksi Sebaran Gas Metana (CH4) di TPA Pakusari Jember Menggunakan Sensor TGS 2611," Skripsi, Universitas Jember, Jember, 2017.

[7] R. Alfanz, A. Nurhadi, and J. A. Laksmono, "Perancangan Dan Implementasi Sistem Monitoring Produksi Biogas Pada Biodigister," Jurnal Nasional Teknik Elektro, vol. 5, no. 1, pp. 2-8, 2016.

[8] N. Maulana, O.D. Nurhayati, and E.D. Widianto," Perancangan Sistem Sensor Pemonitor Lingkungan Berbasis Jaringan Sensor Nirkabel," Jurnal Teknologi dan Sistem Komputer, vol. 4, no.2, pp. 353-360, 2016

[9] E.D. Widianto, A.F. Rochim, and O.D. Nurhayati, "WSN Infrastructure for Green Campus Development," in Proc. Int. Conf. On Information Technology Systems and Innovation (ICITSI), Bali, 2015.

[10] F. Z. Rachman, "Smart Home Berbasis IoT," dalam Prosiding SNITT Poltekba, 2017, pp. 369-374.

[11] F. Z. Rachman, A. Armin, N. Yanti, and Q. Hidayati, "Implementasi Jaringan Sensor Nirkabel Zigbee Menggunakan Topologi Mesh Pada Pemantauan Dan Kendali Perangkat Ruang," Jurnal Teknologi Informasi dan Ilmu Komputer, vol. 4, no. 3, pp. 201-206, 2017. 
[12] F. Z. Rachman, "Prototype Development of Monitoring System in Patient Infusion with Wireless Sensor Network," in Proc. 2015 International Seminar on Intelligent Technology and Its Applications (ISITIA), 2015.

[13] B. Preveze and A. Şafak, "Throughput Improvement of Mobile Multi-Hop Wireless
Networks," International Journal of Wireless \& Mobile Networks, vol. 2, no. 3, pp. 120-139, 2010.

[14] N. Nurazizah, O. D. Nurhayati, and E. D. Widianto, "Perancangan Protokol Komunikasi untuk JSN (Jaringan Sensor Nirkabel) pada Kampus Hijau," Jurnal Teknologi dan Sistem Komputer, vol. 4, no. 2, pp. 344-352, 2016. 